\title{
Aligning Pacific Cocoa Genetics to Productivity and Quality for the Craft Speciality Chocolate Market ${ }^{\dagger}$
}

\author{
Natalie Dillon ${ }^{1, *}$, Yan Diczbalis ${ }^{2}$, John Oakeshott ${ }^{3}$ and Paitia Nagalevu ${ }^{3}$ \\ 1 Department of Agriculture and Fisheries, Mareeba 4880, Australia \\ 2 Department of Agriculture and Fisheries, South Johnstone 4859, Australia; Yan.Diczbalis@daf.qld.gov.au \\ 3 Pacific Community, Suva, Fiji; johno@spc.int (J.O.) piatian@spc.int (P.N.) \\ * Correspondence: Natalie.Dillon@daf.qld.gov.au \\ + Presented at the third International Tropical Agriculture Conference (TROPAG 2019), Brisbane, Australia, \\ 11-13 November 2019.
}

Published: 14 February 2020

\begin{abstract}
Cocoa (Theobroma cacao L.) is an important agricultural export of South Pacific countries, providing livelihoods for an estimated 310,000 people. The wet tropical coast of Far North Queensland has also started producing cocoa for a local boutique chocolate making industry. Although the volumes of cocoa produced are small by global standards, Pacific island and north Australian cocoa is well placed to compete in the high-value, low-volume markets-based on fine flavour, unusual genetic resources and novel 'single origin' branding. A member of the Malvaceae family, cocoa has its origins in Central and South America. First domesticated over 2000 years ago, cocoas' global dispersal was mediated by humans and cultivation is now widespread across the humid tropics. The use of molecular markers to characterize the diversity of genetic resources available and identify superior genetic material is vital to the continued improvement and selection of clones. This work used single nucleotide polymorphism (SNP) markers to identify the parentage of Pacific island cocoa selections in relation to the 10 distinct cocoa families formerly identified from the original Central and South American populations. On farm collections from Pacific island countries has revealed distinct geographic cocoa populations. Specific populations show strong Criollo parentage, a source of fine flavour qualities, while others exhibit a high component of Amelonado parentage. Small populations showed a higher percentage of IMC, Parinari, National or Scavina parentage. Production and quality data linked to these populations assists to identify superior parentage to enable local programs to rapidly bring these into commercial production thereby improving cocoa productivity and quality in the Pacific.
\end{abstract}

Keywords: Theobroma cacao; germplasm; genetic diversity, molecular markers, SNP

Funding: This research was funded by the Australian Centre for International Agricultural Research (ACIAR), project number HORT/2014/078.

Acknowledgments: We acknowledge the technical support of Ms Louise Hucks and our partner country collaborators, their institutions and growers for assisting us with genetic collection of Theobroma cacao. In particular we would like to acknowledge Petelo Lepou (MAF, Samoa), Sefanaia Nakidakida (MOA, Fiji), Tiata Sileye (VARTC, Vanuatu), and Elison Toramo (MAL, Solomon Islands).

Conflicts of Interest: The author declares no conflict of interest.

(C) 2020 by the authors. Licensee MDPI, Basel, Switzerland. This article is an open access article distributed under the terms and conditions of the Creative Commons Attribution (CC BY) license (http://creativecommons.org/licenses/by/4.0/). 